\title{
DTwP-HB-Hib: antibody persistence after a primary series, immune response and safety after a booster dose in children 18-24 months old
}

Hartono Gunardi ${ }^{1 *}$, Kusnandi Rusmil ${ }^{2}$, Eddy Fadlyana ${ }^{2}$, Soedjatmiko ${ }^{1}$, Meita Dhamayanti ${ }^{2}$, Rini Sekartini ${ }^{1}$, Rodman Tarigan², Hindra Irawan Satari ${ }^{1}$, Bernie Endyarni Medise ${ }^{1}$, Rini Mulia Sari ${ }^{3}$, Novilia Sjafri Bachtiar ${ }^{3}$, Cissy B. Kartasasmita ${ }^{2}$ and Sri Rezeki S. Hadinegoro'

\begin{abstract}
Background: The new combination of DTwP-HB-Hib vaccines has been developed in Indonesia following World Health Organization (WHO) recommendation and integrated into national immunization program. The aims of the study were to measure 1) antibody persistence 12-18 months after a primary series, 2) immune response and safety after a booster dose of DTwP-HB-Hib.

Methods: This was a multi-center, open-labeled, prospective, interventional study. Subjects who had received complete primary dose of DTwP-HB-Hib vaccine from the previous phase III trial were recruited in this trial. Subjects were given one dose of DTwP-HB-Hib (Pentabio ${ }^{\oplus}$ ) booster at age 18-24 months old. Diphtheria, tetanus, pertussis, hepatitis B, Hemophilus influenza type B antibodies were measured before and after booster to determine antibody persistence and immune response. Vaccine adverse events were assessed immediately and monitored until 28 days after the booster recorded with parent's diary cards.
\end{abstract}

Results: There were 396 subjects who completed the study. Increased proportion of seroprotected subjects from pre-booster to post-booster were noted in all vaccine antigens: 74.5 to $99.7 \%$ for diphtheria; 100 to $100 \%$ for tetanus; 40.4 to $95.5 \%$ for pertussis; 90.2 to $99.5 \%$ for hepatitis B; and 97.7 to $100 \%$ for Hib. Common systemic adverse events (AEs) were irritability (23.7-25\%) and fever (39.9-45.2\%). Local AEs such as redness, swelling, and induration were significantly less common in the thigh group $(7.7,11.3$, and $7.1 \%)$ than in the deltoid group (28.9, 30.7, and 25\%) ( $P<0.001)$. Most AEs were mild and resolved spontaneously within three-day follow-up period.

Conclusions: Booster of DTwP-HB-Hib vaccine at age 18-24 months is required to achieve and maintain optimal protective antibody. The vaccine is safe and immunogenic to be used for booster vaccination.

Trial registration: NCT02095314 (retrospectively registered, March 24, 2014).

Keywords: Booster dose, DTwP-HB-Hib vaccine, Immunogenicity, Safety, Children

\footnotetext{
* Correspondence: hartono@ikafkui.net

${ }^{1}$ Department of Child Health, Faculty of Medicine, Universitas Indonesia/Dr.

Cipto Mangunkusumo Hospital, JI. Diponegoro No 71, Jakarta 10430,

Indonesia

Full list of author information is available at the end of the article
}

(c) The Author(s). 2018 Open Access This article is distributed under the terms of the Creative Commons Attribution 4.0 International License (http://creativecommons.org/licenses/by/4.0/), which permits unrestricted use, distribution, and reproduction in any medium, provided you give appropriate credit to the original author(s) and the source, provide a link to the Creative Commons license, and indicate if changes were made. The Creative Commons Public Domain Dedication waiver (http://creativecommons.org/publicdomain/zero/1.0/) applies to the data made available in this article, unless otherwise stated. 


\section{Background}

Infections related with vaccine-preventable diseases including hepatitis $\mathrm{B}$, diphtheria, pertussis, and Haemophilus influenzae type B (Hib) were accounted for high morbidity and mortality among children younger than 5 years of age in many underdeveloped countries [1-4]. In accordance with the Expanded Program on Immunization (EPI) recommendation, the Indonesian National Immunization schedule comprises primary vaccination with 3 doses of DTwP-HB-Hib at 2, 3, and 4 months, followed by a booster dose at age 18-24 months. DTwP-HB-Hib is a new vaccine produced by Bio Farma, Indonesia, combining diphtheria toxoid and tetanus toxoid, inactive pertussis bacteria, hepatitis B surface antigen, and Hib [5]. Combination vaccine reduces number of injections, number of visits to healthcare or hospital, cost, discomfort; these ultimately increase parental compliance and improve immunization coverage rates [6, 7].

In India, DTwP-HB-Hib pentavalent vaccine trial showed low reactogenicity, minimal adverse events (AEs), and high level of seroprotective rates $[8,9]$. A randomized trial in Latin American children has also shown that primary and booster vaccination with a DTwP-HB-Hib combination vaccine showed good seroprotection rate and good persistence of antibodies against all vaccine antigens. The vaccine was also well-tolerated as primary and booster doses [10]. However, immunogenicity and safety of DTwP-HB-Hib combined vaccine has not been well understood in Indonesia, especially as a booster dose vaccination.

This study was a follow-up of the previous phase III study [11]. The objectives of this study were to measure antibody persistence after three primary doses at age 2,4,6 months old, to asses immune response, and to ensure safety of a booster dose of DTwP-HB-Hib vaccine.

\section{Methods}

\section{Study design and population}

This open-labeled, prospective, interventional and multicenter trial was conducted from March to October 2014 in Bandung (Group A) and Jakarta (Group B), Indonesia. The main criteria of subjects were children aged 1824 months who had received hepatitis B birth dose and three primary doses of DTwP-HB-Hib vaccine from the previous Phase III trial recruited from three primary health centers in Bandung (Group A) and three primary health centers in Jakarta (Group B) [11].

Exclusion criteria in this trial were mild, moderate or severe illness, especially infectious diseases or fever (axillary temperature $\geq 37.5^{\circ} \mathrm{C}$ on day 0 ); history of allergy to any components of the vaccines; history of uncontrolled coagulopathy or blood disorders contraindicated intramuscular injection; history of acquired immunodeficiency (including HIV infection); received a treatment likely to alter immune response in the previous 4 weeks (e.g. intravenous immunoglobulin, blood-derived products or long-term corticosteroid therapy ( $>2$ weeks); receiving other vaccines within 1 month prior to trial enrollment; any abnormalities or chronic diseases determined by investigators that might interfere the trial objectives; and children with history of either diphtheria, tetanus, pertussis, Hib, and hepatitis B infection.

All subjects were recruited following written form of informed consent authorized by parents or legal representative after the explanation of the trial, potential risks, and his/her obligations. The study protocol had been approved by the Quality Assurance Division of Bio Farma, the Institutional Ethics Committee, and Indonesian Regulatory Authorities. This trial was conducted in accordance with ICH Good Clinical Practice guidelines and local regulatory requirement.

\section{Study procedure}

There were two visit in the study. At the first visit, blood sample from the subjects aged 18-24 months (1218 months after the last dose of three primary doses) were obtained for pre-booster antibody titer. Then each subject was given one dose $(0.5 \mathrm{~mL})$ of DTwP-HB-Hib vaccine as a booster, intra-muscularly into the middle-third anterolateral region of the thigh or the deltoid muscle with a 23G, $25 \mathrm{~mm}$ needle. Anterolateral thigh muscle was the preferred site but the deltoid muscle could also serve as site of injection if pediatrician considered the muscle mass was adequate.

After the booster vaccination, all parents were given a diary to record information for any local and systemic adverse events (AEs) until 28 days after the vaccination. Collection of any local or systems AEs within 3 days after immunization were conducted by a nurse or designated person by home visit or phone call.

At the second visit (28 days after the booster vaccination), blood samples were acquired from the subjects to measure post-booster antibody. Subjects' diary were then reviewed for any notes in local and systemic AEs.

\section{Study vaccine}

DTwP-HB-Hib vaccine (Pentabio ${ }^{\circ}$, batch number 5010613, with expired date: June 2015) used in this study were manufactured by Bio Farma, Bandung, Indonesia. Each $0.5 \mathrm{~mL}$ dose of vaccine contained $\geq 30$ IU of purified diphtheria toxoid, $\geq 60$ IU of purified tetanus toxoid, $\geq 4$ IU of inactivated Bordetella pertussis, $10 \mu \mathrm{g}$ hepatitis B surface antigen (HBsAg, recombinant), $10 \mu \mathrm{g}$ Hib in the form of polyribosil-ribitol-phosphate (PRP) conjugated to tetanus toxoid, $1.5 \mu \mathrm{g}$ aluminium phosphate, $4.5 \mathrm{mg}$ sodium chloride, and $0.025 \mathrm{mg}$ thimerosal. Vaccines were stored in the refrigerator at temperature $+2^{\circ}$ to $+8^{\circ} \mathrm{C}$ (as standart protocol) at the clinical trial centers to assure quality. 


\section{Blood sampling and antibody measurement}

For each subject, $4 \mathrm{~mL}$ of blood was drawn in vacutainer tubes and then coded. After clotted at room temperature in $30 \mathrm{~min}$ to $2 \mathrm{~h}$, each speciment was centrifuged at $3000 \mathrm{rpm}$ for $15 \mathrm{~min}$ and the sera stored in cryotubes within $24 \mathrm{~h}$ after sampling. Sera of the coded samples were stored at $-20 \mathrm{C}$.

Serology antibody testing was started after the samples had been blinded. The blinding code and list were prepared by the statistician and witnessed by the investigators.

Serology assays, except for anti-HBs, were conducted in Immunology Laboratory of Product Evaluation Department of Bio Farma by technicians who were blinded to samples' visit. Test for anti-HBs was conducted in Prodia Laboratory which had been assessed by Quality Assurance of Bio Farma and had been certificated by ISO 9001 and National Accreditation Committee. Tetanus and diphtheria antibody were measured by validated ELISA. Pertussis antibody was measured by microagglutination method. Antibody to hepatitis B surface antigen (anti-HBs) was measured by Chemiluminescent Microparticle Immunoassay (CMIA) AUSAB reagent kit by Abbott. Antibody to PRP was measured by using Improved Phipps ELISA; a competitive ELISA was used for measuring the levels of serum antibody to Haemophilus influenzae type B. All antibody assays were validated previously.

\section{Measures}

This study measured antibody persistence after three doses of primary vaccinations and immune response after a single booster dose at 18-24 months of age. Antibody persistence is defined as having antibody level above the protective threshold for each given vaccination after primary doses. Immune response after booster was expressed in three parameters: (1) seroprotection (antibody level above the basic protective threshold), (2) seroconversion (conversion of seronegative to seropositive), and (3) four-times increase of antibody level $[12,13]$. Primary outcome was the short-term or basic protective antibody, defined as: diphtheria antibody $\geq 0.01 \mathrm{IU} / \mathrm{mL}$, tetanus antibody $\geq 0.01 \mathrm{IU} /$ $\mathrm{mL}$, pertussis antibody $\geq 1 / 40$, hepatitis $\mathrm{B}$ antibody $\geq 10$ $\mathrm{mIU} / \mathrm{mL}$, and Hib antibody titer (PRP) $\geq 0.15 \mu \mathrm{g} / \mathrm{mL}$. Secondary outcome was long-term or full protective antibody, defined as diphtheria antibody $\geq 0.1 \mathrm{IU} / \mathrm{mL}$, tetanus antibody $\geq 0.1 \mathrm{IU} / \mathrm{mL}$, pertussis antibody $\geq 1 / 80$, and Hib antibody titer (PRP) $\geq 1 \mu \mathrm{g} / \mathrm{mL}$ [14-18].

\section{Safety assessment}

Immediate local and systemic AEs 30 min after vaccination were observed and recorded at the health centers. A digital thermometer, a plastic measuring scale, and a diary card were provided for the parents to measure and record axillary temperature and the size of redness and swelling, respectively. Appearance, duration, and intensity of any local or systemic adverse events (indicated as 1 [mild], 2 [moderate], or 3 [severe]) were recorded at home. Local reactions were defined as the presence of local pain, redness, induration, or swelling at the injection site; the systemic events were defined as the occurrence of fever (axillary temperature $\geq 38.0^{\circ} \mathrm{C}$ ), irritability, or both. Local and systemic AEs were recorded in two interval of time: (1) within $30 \mathrm{~min}$ to $72 \mathrm{~h}$ and (2) $72 \mathrm{~h}-28$ days after vaccination.

Vaccine AEs were retrieved by interviewing the parents and assessing the diary card during the follow-up visit.

\section{Statistical analysis}

The vaccine immunogenicity and safety were analyzed using intention-to-treat (ITT) and per-protocol (PP) analyses. Immunogenicity analysis was done regarding response to each vaccine antigen pre- and post-booster. Seroprotection, increase in antibody level, and seroconversion were calculated for each vaccine antigen. AEs were analyzed using Chi-square test with at least $p$ value $<0.05$ considered to be statistically significant.

\section{Results}

There were 399 subjects enrolled at the first visit. These subjects were subsequently divided into two groups: of 238 children in Group A (Bandung); and 161 children in Group B (Jakarta) (Fig. 1). One subject in Group B was lost to follow-up because the child moved to another province, and there were two subjects were withdrawn from the study. After these drop-outs, the total of the subjects were 396 subjects (238 subjects in Group A and 158 subjects in Group B). All subjects were of Indonesian race, with their demographic and baseline characteristics of presented in Table 1.

\section{Diphtheria antibody}

The protective level of diphtheria antibody was $74.5 \%$ prior the booster immunization, and $99.7 \%$ after booster. As many as $87.1 \%$ subjects had increment in their antibody titer $\geq 4$ times, and all of seronegative subjects experinced seroconversion after the administration of booster dose. The Geometric Mean Titer (GMT) of the diphtheria antibody increased 9.4 times (0.054 to 0.508$)$ after booster (Table 2).

\section{Tetanus antibody}

Subjects who had the protective level of tetanus antibody were $100 \%$, before and after the booster. However, there was an increment of GMT 20.6 times, from 0.187 to 3.853 after the booster. The proportion of subjects with 4-times increased in antibody titer was $91.7 \%$ (Table 2). 


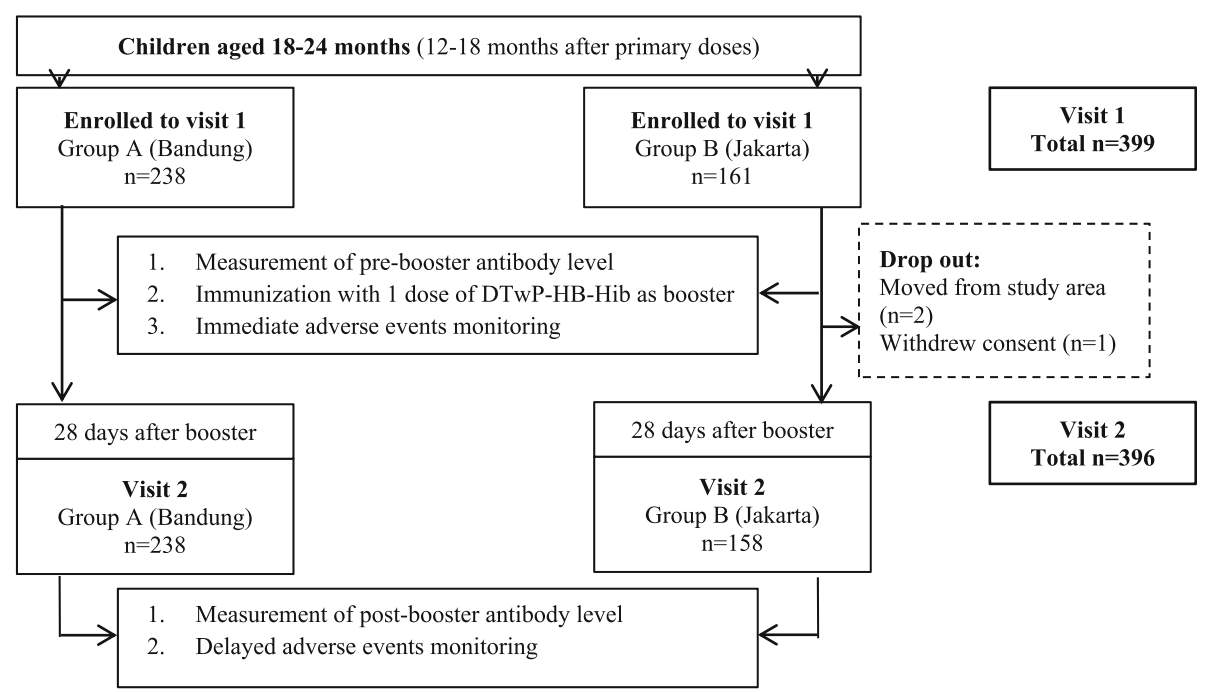

Fig. 1 Subjects recruitment

\section{Pertussis antibody}

The subjects with pertussis micro-agglutination level $\geq$ $1 / 40$ were $40.4 \%$ before booster and this number was increased to $95.5 \%$ after the booster. There were $90.9 \%$ of the subjects whose antibody titer was increased four times from the baseline, and increased of the GMT by 22.8 times, from 28.086 to 639.145 , after the booster (Table 2).

\section{Hepatitis B antibody}

Prior the booster, the proportion of subjects with protective hepatitis B antibody were 90.2, and 99.5\% after booster. As many as $97.2 \%$ subjects had four times increment in their antibody titer and $94.9 \%$ subjects had seroconversion to seropositive. The GMT of hepatitis B antibody increased 65.6 times from 85.27 to 5591.13 after booster (Table 2).

\section{Haemophilus influenza B}

The proportion of subjects with protective level of Hib antibody was $97.7 \%$ before booster and $100 \%$ after booster. As many as $82.3 \%$ subject had 4-times increment in antibody titer, and all subjects who previously were seronegative had converted to seropositive after the booster.

Table 1 Demographic characteristics of subjects

\begin{tabular}{llll}
\hline Description & Group A $(N=238)$ & Group B $(N=161)$ & Total \\
\hline Gender & & & \\
Male $(\mathrm{n})$ & 112 & 69 & $181(45.4 \%)$ \\
Female $(\mathrm{n})$ & 126 & 92 & $218(45.4 \%)$ \\
Age (months) & & & \\
Mean \pm SD & $19 \pm 0.8$ & $20 \pm 0.9$ & $20 \pm 1.0$ \\
Min-max & $18-22$ & $19-24$ & $18-24$ \\
\hline
\end{tabular}

Overall, the GMT of Hib antibody increased 20.7 times, from 3.399 to 70.226 after booster (Table 2).

\section{Local adverse events $\mathbf{3 0}$ min after booster vaccination}

Local AEs were reported in $17.3 \%$ subjects in the deltoid group and $14.9 \%$ subjects in the thigh group within 30 min after vaccination. The pain was reported in $10.8 \%$ subjects in the deltoid group and in $8.3 \%$ subjects in the thigh group. All of the symptoms were slightly less common in the thigh than in the deltoid group, but not statistically significant $(P=0.515)$.

Systemic adverse events $\mathbf{3 0}$ min after booster vaccination The most common AE was irritability, which was found in $11.7 \%$ subjects of the deltoid group and $6.5 \%$ of the thigh group.

\section{Local adverse events $>\mathbf{3 0}$ min to $\mathbf{7 2} \mathrm{h}$ after booster vaccination}

Local AEs were reported in 51.3\% subjects of the deltoid group and $41.7 \%$ of the thigh group within $30 \mathrm{~min}$ to $72 \mathrm{~h}$ following booster vaccination. All of the symptoms were less common in the thigh group than in the deltoid group. Pain was reported in $43.4 \%$ subjects in the deltoid group and $38.1 \%$ subjects in the thigh group. Local AEs such as redness, swelling, and induration were found significantly less common in the thigh group $(7.7,11.3,7.1 \%)$, compared to the deltoid group $(28.9,30.7,25 \%)(P<0.001)$ (Fig. 2).

\section{Systemic adverse events $>30$ min to $72 \mathrm{~h}$ after booster} vaccination

There were $42.1 \%$ subjects in the deltoid group and $51.2 \%$ subjects in the thigh group who had systemic 
Table 2 Summary of pre-booster and post-booster antibody level of tested antibodies*

\begin{tabular}{|c|c|c|c|c|}
\hline Antibody & $N=396$ & Subjects (\%) & $95 \% \mathrm{Cl}$ & GMT(Range) \\
\hline \multicolumn{5}{|l|}{ Diphtheria } \\
\hline Pre-booster titer (IU/mL) & & & & $0.054(0.047-0.061)$ \\
\hline Anti-D $\geq 0.01^{a}$ & 295 & 74.5 & & \\
\hline Anti-D $\geq 0.1^{b}$ & 81 & 20.5 & $16.8-24.7$ & \\
\hline Post-booster titer (IU/mL) & & & & $0.508(0.446-0.580)$ \\
\hline Anti- $D \geq 0.01^{a}$ & 394 & 99.7 & & \\
\hline Anti- $D \geq 0.1^{b}$ & 344 & 87.1 & $83.4-90.0$ & \\
\hline Increased antibody titer ${ }^{c}$ & 345 & 87.1 & & \\
\hline Seroconversion $^{d}$ & 98/98 & 100 & & \\
\hline \multicolumn{5}{|l|}{ Tetanus } \\
\hline Pre-booster titer (IU/mL) & & & & $0.187(0.169-0.206)$ \\
\hline Anti-tetanus $\geq 0.01^{\mathrm{a}}$ & 396 & 100 & & \\
\hline Anti-tetanus $\geq 0.1^{\mathrm{b}}$ & 286 & 72.2 & $67.4-76.2$ & \\
\hline Post-booster titer (IU/mL) & & & & $3.853(3.531-4.205)$ \\
\hline Anti-tetanus $\geq 0.01^{\mathrm{a}}$ & 396 & 100 & & \\
\hline Anti-tetanus $\geq 0.1^{b}$ & 394 & 95.5 & $98.2-99.9$ & \\
\hline Increased antibody titer ${ }^{c}$ & 363 & 91.7 & & \\
\hline \multicolumn{5}{|l|}{ Pertussis } \\
\hline Pre-booster titer & & & & $28.086(24.791-31.812)$ \\
\hline$\geq 1 / 40^{\mathrm{a}}$ & 160 & 40.4 & $35.7-45.3$ & \\
\hline$\geq 1 / 80^{b}$ & 99 & 25.0 & $21.0-29.5$ & \\
\hline Post-booster titer & & & & $639.145(550.807-741.651)$ \\
\hline$\geq 1 / 40^{\mathrm{a}}$ & 378 & 95.5 & $92.9-97.1$ & \\
\hline$\geq 1 / 80^{b}$ & 367 & 92.7 & $89.7-94.9$ & \\
\hline Increased antibody titer ${ }^{c}$ & 360 & 90.9 & & \\
\hline \multicolumn{5}{|l|}{ Hepatitis B } \\
\hline Pre-booster titer (mIU/mL) & & & & 85.27 (74.199-98.016) \\
\hline Anti-HBs $\geq 10$ & 357 & 90.2 & $86.8-92.7$ & \\
\hline Post-booster titer (mIU/mL) & & & & $5591.13(4761.02-6564.47)$ \\
\hline Anti-HBs $\geq 10$ & 394 & 99.5 & $97.8-98.7$ & \\
\hline Increased antibody titer ${ }^{c}$ & 385 & 97.2 & & \\
\hline Seroconversion $^{d}$ & $37 / 39$ & 94.9 & & \\
\hline \multicolumn{5}{|l|}{ PRP-T (Hib) } \\
\hline Pre-booster titer $(\mu \mathrm{g} / \mathrm{mL})$ & & & & 3.399 (3.006-3.844) \\
\hline Anti-Hib $\geq 0.15^{a}$ & 387 & 97.7 & & \\
\hline Anti-Hib $\geq 1.0^{b}$ & 343 & 86.6 & $82.9-89.6$ & \\
\hline Post-booster titer ( $\mu \mathrm{g} / \mathrm{mL})$ & & & & $70.226(61.249-80.501)$ \\
\hline Anti-Hib $\geq 0.15^{\mathrm{a}}$ & 396 & 100 & & \\
\hline Anti-Hib $\geq 1.0^{b}$ & 394 & 99.5 & $98.2-99.9$ & \\
\hline Increased antibody titer ${ }^{c}$ & 326 & 82.3 & & \\
\hline Seroconversion $^{d}$ & $9 / 9$ & 100 & & \\
\hline
\end{tabular}

"Based on per-protocol analysis

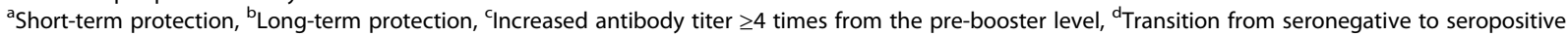




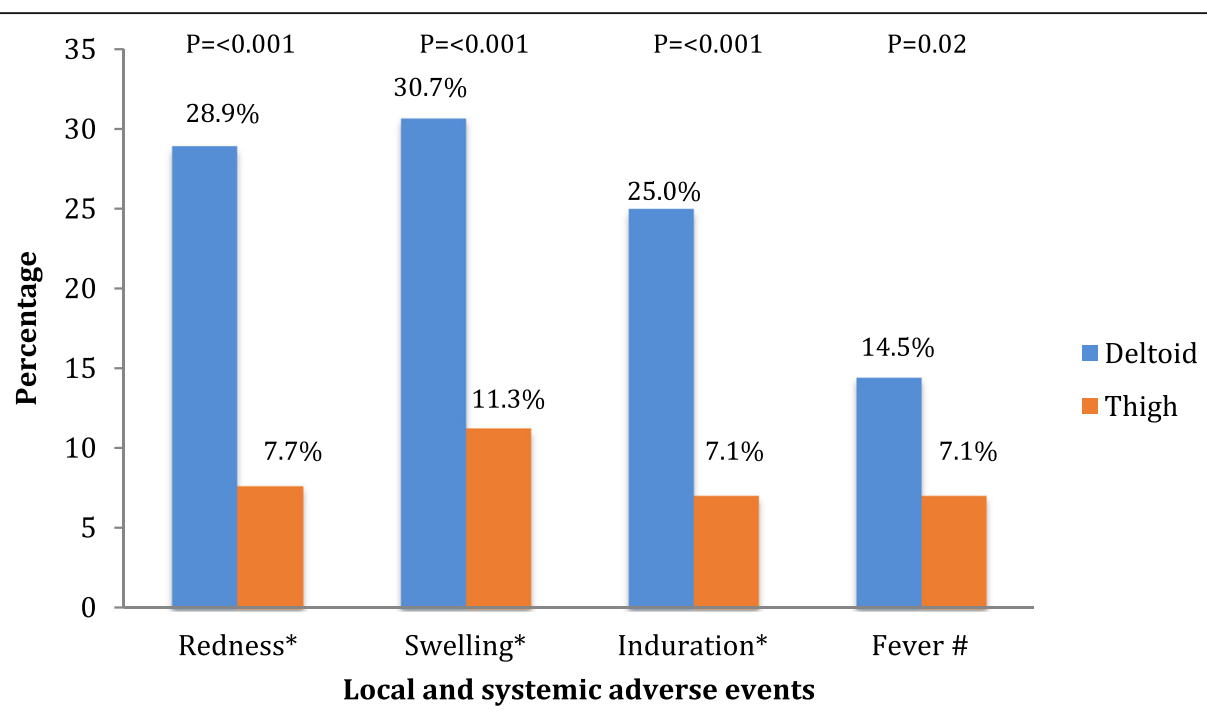

Fig. 2 Local and systemic adverse events

*local and systemic adverse events 30 minutes - 72 hours, \#Systemic adverse events 72 hours - 28 days, No significant differences in AEs for pain, irritability, and others between deltoid and thigh group

adverse events in $>30$ min to $72 \mathrm{~h}$ after vaccination. The most common systemic AE was irritability $(39.9 \%$ in deltoid group and $45.2 \%$ in thigh group), with the second most common systemic AE was fever (23.7\% in deltoid group and $25 \%$ in thigh group). Both occurred slightly less common in the deltoid groups.

\section{Local adverse events $>72 \mathrm{~h}$ to 28 days after booster vaccination}

No local reaction occurred within 72 h to 28 days after the booster vaccination, except 3 subjects with induration in deltoid group.

\section{Systemic adverse events $>72 \mathrm{~h}$ to 28 days after booster vaccination}

There were $23.2 \%$ subjects in the deltoid group and $16.1 \%$ subjects in the thigh group who were reported to have systemic adverse events within $72 \mathrm{~h}$ to 28 days after vaccination. The most common symptom reported was fever $(14.5 \%$ in the deltoid group vs. $7.1 \%$ in the thigh group), which statistically more significant to be found in the deltoid group ( $P=0.02$, Fig. 2$)$. All of the other symptoms (irritability and others) were found to be slightly less common in the thigh group than in the deltoid group, but not statistically significant.

\section{Local and systemic reaction intensity}

Most of the adverse events that were reported were mild and resolved spontaneously within the $72 \mathrm{~h}$ follow-up period. There was one report of acute diarrhea as a serious $\mathrm{AE}$ from Group B, which was classified as unrelated. The subject was recovered after several days of hospitalization. There was no other vaccine-related serious AE reported.

\section{Discussion}

This study has demonstrated good immunogenicity and tolerability of the new combined DTwP-HB-Hib (Pentabio ${ }^{\circ}$ ) vaccine as a booster dose in children age 18-24 months old. Although the persistence of antibody following the primary doses were quite good for each vaccine antigen, there were some degrees of waning immunity during 18-24 months of age, especially diphtheria and pertussis. This justified the necessity for a booster dose in children age 18-24 months.

In a previous study, 1 month after the third dose of DTwP-HB-Hib (Pentabio ${ }^{\circ}$ ) as primary vaccination, most of the children $(84-100 \%)$ had protective antibody level [11]. In this study, the antibodies prior booster vaccinations were low in subjects with protective antibody of diphtheria and pertussis (74.5 and $40.4 \%$, respectively). After the booster, the seroprotection had increased to 99.7 and $95.5 \%$ for diphtheria and pertussis, respectively. Another DTPw-HB-Hib vaccine trial in El Salvador finds the seroconversion of $B$. pertussis after a booster dose was $94.4 \%$. In addition, a trial in Latin America finds at least $99.1 \%$ had the seroprotective level of antibodies against diphtheria, tetanus and hepatitis $B[10,19]$.

Currently, there is no international standard definition determined for the seroprotection for B. pertussis. A study in France used the ratio 1: 80 as cut-off, but in it was stated that the cut-off might had been too high as a cutoff [20]. We used the $1 / 40$ as cut-off, only $40.4 \%$ of our subjects had the seroprotection before the booster doses. However, this proportion had increased greatly to $95.5 \%$ after one dose of booster. The 1/40 cut-off was also used in the pertussis outbreak in a university in Japan [21]. In this study, the protective titer was found in $92.7 \%$ subjects for the long-term protection of using the 1/80 cut-off. 
The persistent protective antibody after three primary doses in children aged $18-24$ months was $90.2 \%$ for hepatitis B, and $97.7 \%$ for Hib. After primary immunization, anti-HBs concentrations wane quite rapidly within the first year and more slowly thereafter. Even with the waning immunity, the immune memory to hepatitis B continues to persist over a longer period. Protective antibody had risen to 99.5 and 100\%; and following the booster dose, seroconversion occurred in 94.9 and $100 \%$ subjects to hepatitis B and Hib, respectively, indicating effective priming and induction of the immune memory [22].

The long-term protection of tetanus from our earlier study was $72.2 \% 1$ month after primary DTP-HB-Hib vaccination [11], then decreased to $72.2 \%$ at $18-24$ months of age. After the booster, the long-term protection had increased to $95.5 \%$ with the GMT level of $3.85 \mathrm{IU} / \mathrm{mL}$, which will provide 3-5 years of protection [23].

DTwP-HB-Hib vaccine was found to be highly immunogenic in our booster vaccination study. One month following the booster vaccination of this vaccine, our study finds at least $95.5 \%$ of the study subjects reached protective levels of antibodies (seroprotected) against the antigens employed in the vaccine. Another report of DTwP-HB-Hib (Quinvaxem ${ }^{\circ}$ ) immunogenicity showed 99.4\% seroprotection at 1-month after booster dose [24]. Other previous studies of similar pentavalent vaccine in Latin America and Costa Rica showed that it could induce both persisting immunity and boostable memory, therefore provided an efficient and reliable way of implementing this vaccine to the routine program $[25,26]$.

In this study, no serious adverse events were considered related to vaccine or procedure. This study has demonstrated that the occurrence of local AEs such as redness, swelling and induration within $30 \mathrm{~min}-72 \mathrm{~h}$, and fever as systemic AE in $72 \mathrm{~h}-28$ days were significantly less common in the thigh group than in the deltoid group. This findings are similar to a previous study conducted in Vaccine Safety Datalink population that included 1.4 million of children in the USA, which finds injection in thigh was associated with significantly lower risk of local reaction to DTaP vaccination among children 1-2 years of age. This finding supports the current recommendation for thigh as intramuscular site injection in this age group [27].

The three doses of primary immunization and a booster dose of DTwP-HB-Hib were all immunogenic and well-tolerated by the study subjects. DTwP-HB-Hib vaccine is a suitable for immunization program in developing countries. $[9,11,19,25,26]$.

\section{Limitation of study}

There were only 399 (69.4\%) out of 575 subjects were recruited. A total of 396 subjects who completed the DTwP-HB-Hib primary immunization were analyzed.
The reason for this limitation was due to unpredictable heavy flood in the study area, which caused so many subjects moved to other areas. Regardless the limitation, this was the first study of immunogenicity and safety of DTwP-HB-Hib booster in Indonesian children.

\section{Conclusions}

The new combination of DTwP-HB-Hib vaccines (Pentabio) as a booster at age 18-24 months is necessary to achieve and maintain optimal protective antibody. The vaccine is safe and immunogenic to be used for booster vaccination.

\section{Abbreviations}

DTwP: Diphtheria tetanus whole-cell pertussis; GMT: Geometric mean titer; HB: Hepatitis B; HBsAg: Hepatitis B surface antigen; Hib: Haemophilus influenza type b; PRP: Polyribosil-ribitol-phosphate

\section{Acknowledgments}

PT Bio Farma was the funding stakeholder of this study. The authors would like to thank all of the children and parents who participated in this study, head of Bandung District Health Office, Jakarta Province Health Office, head and staff of Garuda, Ibrahim Adjie, Puter Primary Health Center in Bandung; head and staff of Jatinegara, Mampang, and Tebet Primary Health Center in Jakarta for their supports. We would also like to express our appreciation for the tremendous support of Indonesian National AEFI Committee as auditor of SAEs in this study. We also thank Mr. Hadyana Sukandar for his statistical work in this study, and Dr. Natharina Yolanda for her invaluable editorial assistance.

\section{Funding}

This study was funded by PT Bio Farma, number 06815/DIR/XII/2013 (Bandung site) and 06818/DIR/XII/2013 (Jakarta site).

\section{Availability of data and materials}

The datasets analyzed during the current study available from the corresponding author on reasonable request.

\section{Authors' contributions}

KR was a national principal investigator and principal investigator in Bandung city. HG was the principal investigator in Jakarta city. KR, HG, EF, RMS, and NSB conceived the study and its design. $\mathrm{HG}, \mathrm{KR}$, EF, and $\mathrm{S}$ wrote and review the manuscript. MD and RT reviewed the design, recruited the subjects and conducted the study in Bandung city. S, RS, BEM and HIS reviewed the design, recruited the subjects and conducted the study in Jakarta city. SRH was the medical advisor of Jakarta site and reviewed the study and manuscript. CBK was the medical advisor of Bandung site and reviewed the study and manuscript. All authors read and approved the final manuscript.

\section{Ethics approval and consent to participate}

This trial has been approved by Health Research Ethics Committee Faculty of Medicine Universitas Padjajaran Bandung (418/UN6.C2.1.2/KEPK/PPN/2013) and The Ethics Committee of the Faculty of Medicine, University of Indonesia (735/H2.F1/ETIK/2013)

A written form of informed consent was obtained from every child's parent or legal guardian before the recruitment.

\section{Competing interests}

Hartono Gunardi, Kusnandi Rusmil, Eddy Fadlyana, Soedjatmiko, Meita Dhamayanti, Rini Sekartini, Rodman Tarigan, Hindra Irawan Satari, Bernie Endyarni Medise, Cissy B Kartasasmita, Sri Rezeki S Hadinegoro, received grant support through their institutions. Rini Mulia Sari and Novilia Sjafri Bachtiar were employees of PT Bio Farma at the time of the conduct of this study and manuscript preparation.

\section{Publisher's Note}

Springer Nature remains neutral with regard to jurisdictional claims in published maps and institutional affiliations. 


\section{Author details}

'Department of Child Health, Faculty of Medicine, Universitas Indonesia/Dr. Cipto Mangunkusumo Hospital, Jl. Diponegoro No 71, Jakarta 10430, Indonesia. ${ }^{2}$ Department of Child Health, Faculty of Medicine, Padjadjaran University/Dr. Hasan Sadikin Hospital, Jl. Pasteur No 38, Bandung 40161, Indonesia. ${ }^{3}$ PT Bio Farma, Jl. Pasteur No 28, Bandung, Jawa Barat, Indonesia.

Received: 11 July 2017 Accepted: 3 May 2018

Published online: 28 May 2018

\section{References}

1. CDC. Haemophilus influenzae type B. In: Hamborsky J, Kroger A, Wolfe S, editors. Epidemiology and prevention of vaccine-preventable diseases. 13th ed. Washington D.C.: Public Health Foundation; 2015. p. 119-34.

2. Pertussis CDC. In: Hamborsky J, Kroger A, Wolfe S, editors. Epidemiology and prevention of vaccine-preventable diseases. 13th ed. Washington D.C. Public Health Foundation; 2015. p. 261-78.

3. CDC. Hepatitis B. In: Hamborsky J, Kroger A, Wolfe S, editors. Epidemiology and prevention of vaccine-preventable diseases. 13th ed. Washington D.C. Public Health Foundation; 2015. p. 149-74

4. CDC. Diphtheria. In: Hamborsky J, Kroger A, Wolfe S, editors. Epidemiology and prevention of vaccine-preventable diseases. 13th ed. Washington D.C. Public Health Foundation; 2015. p. 107-18.

5. Rusmil K, Fadlyana E, Bachtiar NS. Safety and immunogenicity of the DTP/ HB/Hib combination vaccine: phase I study. Paed Indones. 2013;53:309-14.

6. Decker MD. Principles of pediatric combination vaccines and practical issues related to use in clinical practice. Pediatr Infect Dis J. 2001;20(11 Suppl):S10-8.

7. Marshall GS, Happe LE, Lunacsek OE, Szymanski MD, Woods CR, Zahn M, et al. Use of combination vaccines is associated with improved coverage rates. Pediatr Infect Dis J. 2007;26:496-500.

8. Gandhi DJ, Dhaded SM, Ravi MD, Dubey AP, Kundu R, Lalwani SK, et al. Safety, immune lot-to-lot consistency and non-inferiority of a fully liquid pentavalent DTwp-HepB-Hib vaccine in healthy Indian toddlers and infants. Hum Vaccin Imunother. 2016;12:946-54

9. Sharma H, Yadav S, Lalwani S, Gupta V, Kapre S, Jadhav S, et al. A phase III randomized, controlled study to assess the immunogenicity and tolerability of DTPw-HBV-Hib, a liquid pentavalent vaccine in Indian infants. Vaccine. 2011;29:2359-64.

10. Espinoza F, Tregnaghi M, Gentile A, Abarca K, Casellas J, Collard A, et al. Primary and booster vaccination in Latin American children with a DTPW-HBV/Hib combination: a randomized controlled trial. BMC Infect Dis. 2010;10:297.

11. Rusmil K, Gunardi H, Fadlyana E, Soedjatmiko, Dhamayanti M, Sekartini R, et al. The immunogenicity, safety, and consistency of an Indonesia combined DTP$\mathrm{HB}-$ Hib vaccine in expanded program on immunization schedule. BMC Pediatr. 2015;15:219.

12. Gold R, Barreto L, Ferro S, Thippawong J, Guasparini R, Meekison W, Russell M, et al. Safety and immunogenicity of a fully liquid vaccine containing fivecomponent pertussis-diphtheria-tetanus-inactivated poliomyelitis-Haemophilus influenzae type b conjugate vaccines administered at two, four, six and 18 months of age. Can J Infect Dis Med Microbiol. 2007;18(4):241-8.

13. Nauta J. Statistics in clinical vaccine trials. New York: Springer; 2011. p. 28.

14. WHO. The immunological basis for immunization series. Module 2 diphtheria. Geneva: WHO; 2009. p. 4-19.

15. Borrow R, Balmer $\mathrm{P}$, Roper $M H$. The immunological basis for immunization series. Module 3, tetanus. Geneva: WHO; 2006. p. 2-24.

16. WHO. The immunological basis for immunization series. Module 22 hepatitis B. Geneva: WHO; 2011. p. 2-15.

17. WHO. The immunological basis for immunization series. Module 4: pertussis update; 2009. p. 26-36.

18. WHO. Recommendations for the production and control of Haemophilus influenza type b conjugate vaccine. Technical Report Series 897 Annex 1. Geneva 2000:57-59.

19. Suarez E, Asturias EJ, Hilbert AK, Herzog C, Aeberhard U, Spyr C. A fully liquid DTPw-HepB-Hib combination vaccine for booster vaccination of toddlers in El Salvador. Rev Panam Salud Publica 2010;27:117-124.

20. Relyveld E, Oato NH, Guerin N, Coursaget P, Huet M, Gupta RK. Determination of circulating antibodies directed to pertussis toxin and of agglutinogens in children vaccinated with either the whole cell or component pertussis vaccine in France, Japan and Senegal. Vaccine. 1991;9:843-50.
21. Kamano H, Mori T, Maeta H, Taminato T, Ishida T, Kishimoto N, et al. Analysis of Bordetella pertussis agglutinin titers during an outbreak of pertussis at a university in Japan. Jpn J Infect Dis. 2010;63:108-12.

22. Marshall $H$, Mclntyre $P$, Roberton D, Dinan $L$, Hardt K. Primary and booster immunization with a diphtheria, tetanus, acellular pertussis, hepatitis B (DTPa-HBV) and Haemophilus influenzae type b (Hib) vaccine administered separately or together is safe and immunogenic. Int J Infect Dis. 2010;14:e41-9.

23. World Health Organization (WHO). Tetanus vaccines: WHO position paper. February 2017. Wkly Epidemiol Rec. 2017;92:53-76.

24. Schmid DA, Macura-Biegun A, Rauscher M. Development and introduction of a ready-to-use pediatric pentavalent vaccine to meet and sustain the needs of developing countries-Quinvaxem(R): the first 5 years. Vaccine. 2012;30:6241-8

25. Tregnaghi M, Lopez P, Rocha C, Rivera L, David MP, Ruttimann R, et al. A new DTPW-HB/Hib combination vaccine for primary and booster vaccination of infants in Latin America. Rev Panam Salud Publica. 2006;19:179-88.

26. Faingezicht I, Avila-Aguerro ML, Cervantes $Y$, Fourneau M, Clemens SA. Primary and booster vaccination with DTPw/HB/Hib pentavalent vaccine in Costa Rican children who had received a birth dose of hepatitis B vaccine. Rev Panam Salud Publica. 2002;12:247-57.

27. Jackson LA, Peterson D, Nelson JC, Marcy SM, Naleway AL, Nordin JD, et al. Vaccination site and risk of local adverse events in children 1 through 6 years of age. Pediatrics. 2013;131:283-9.

\section{Ready to submit your research? Choose BMC and benefit from:}

- fast, convenient online submission

- thorough peer review by experienced researchers in your field

- rapid publication on acceptance

- support for research data, including large and complex data types

- gold Open Access which fosters wider collaboration and increased citations

- maximum visibility for your research: over $100 \mathrm{M}$ website views per year

At BMC, research is always in progress.

Learn more biomedcentral.com/submissions 